\title{
Investigating the Mediterranean by seafloor observations: the Eastern branch of the EMSO Ligurian Sea node
}

\author{
M. Locritani, L. Beranzoli*, C. Carmisciano, D. \\ Embriaco, F. Muccini, P. Favali* \\ Istituto Nazionale di Geofisica e Vulcanologia,Roma, Italy \\ (* EMSO Interim Office)

\section{J. Aguzzi} \\ Consejo Superior de Investigaciones Scientifica - Marine \\ Science Institute, Barcelona, Spain \\ A. Benedetti, L. Liggieri \\ Consiglio Nazionale delle Ricerche - Istituto per \\ l'Energetica e le Interfasi, Genova, Italy \\ T. Ciuffardi, S. Cocito, R. Delfanti, E. Fanelli, A. \\ Peirano \\ Agenzia nazionale per le nuove tecnologie, l'energia e lo \\ sviluppo economico sostenibile, La Spezia, Italy
}

\begin{abstract}
The overall objective of this proposal is to build an advanced and original prototype specifically devoted to seafloor and water-column monitoring as starting Italian contribution to the further development of the EMSO Ligurian Sea node. In detail the aim of the observatory is to ensure realtime continuous acquisition of geophysical, oceanographic and biological data by a cable system from a marine depth of about $500 \mathrm{~m}$ to the shore station.
\end{abstract}

Keywords - EMSO; Ligurian Sea; seafloor and water-column observatory

\section{INTRODUCTION}

Environmental problems, such as ecosystem functioning, global change and extreme events, are quite complex and require the understanding of non-linear interactions among non-stationary multi-scale processes. These studies can be made possible by using an integrated approach that combines large amounts of data and modelling to characterize the different temporal and spatial scales and

\author{
E.F. Coelho, R. Stoner \\ NATO STO Centre for Maritime Research and \\ Experimentation (CMRE), La Spezia, Italy \\ L. Dialti, N. Pizzeghello \\ Istituto Idrografico della Marina, Genova, Italy \\ D. Marini, A., Martinelli, M. Stroobant \\ DLTM - Distretto Ligure delle Tecnologie Marine, La \\ Spezia, Italy \\ S. Marini, A. Vetrano \\ Consiglio Nazionale delle Ricerche - Istituto di Scienze \\ Marine, La Spezia, Italy \\ P. Povero \\ Università degli Studi di Genova, Dipartimento di Scienze \\ della Terra, dell'Ambiente e della Vita, Genova, Italy

$$
\begin{gathered}
\text { M. Stifani } \\
\begin{array}{c}
\text { Centro di Supporto e Sperimentazione Navale, } \\
\text { La Spezia, Italy }
\end{array}
\end{gathered}
$$

interrelations among phenomena from the top of the ocean to the seabed. The establishment of marine observatories is a response to these needs. Such observatories are implemented by means of sensor networks, on board of different platforms, covering a diversity of oceanic environments. The Eastern Branch of the EMSO (European Multidisciplinary Seafloor and water-column Observatory; www.emso-eu.org) [1] node in the Ligurian Sea, is seen as an important element of an observatory capable to collect data to understand the coastal-open sea interactions. The integrating feature of the observatory is a comprehensive einfrastructure, whose design is based on loosely-coupled distributed services, and whose elements are expected to reside throughout the physical components; from underwater instruments to autonomous vehicles to deep sea moorings to shore facilities to computing and storage infrastructure. Many large-scale projects have been planned to establish permanent seafloor networks at international level. Canada, USA, Japan, Taiwan, and Europe are the 
major actors [2]; in the European context EMSO is one of these projects and represents a large-scale European Research Infrastructure included since 2006 in the ESFRI Roadmap [3]. EMSO deals with interdisciplinary, longterm, and multi-scale research, incorporating traditional knowledge and modern technologies, with the basic scientific objective of real-time monitoring of environmental processes [4]. EMSO infrastructure includes several fixed-point, seafloor and water-column observatories geographically distributed in key sites of European waters, from the Arctic to the Black Sea through the Mediterranean Sea. EMSO will be the sub-sea segment of the COPERNICUS (former GMES-Global Monitoring for Environment and Security) initiative and will significantly enhance the observational capabilities of the European Member States.

The present status of EMSO includes eight operating nodes equipped with stand-alone (autonomous) observatories, having reduced capability of communication, and with cabled observatories, able to transmit data in real time and fully interactive like NEMO-SN1 in the EMSO Western Ionian Sea node [5].

Presently, the EMSO node in the Ligurian Sea extends over four sites hosting real time mooring of DYFAMED project (DYnamics of Atmospheric Fluxes in the MEDiterranean Sea), subsea autonomous moorings in Var Canyon, realtime data transmission mooring in Nice slope, ANTARES system (Astronomy with a Neutrino Telescope and Abyss environmental RESearch), an Earth-Sea science extension of astrophysics underwater telescope.

This paper describes the upcoming Italian contribution to the improvement of the EMSO node in the Eastern Ligurian Sea.

\section{MOTIVATIONS FOR A PERMANENT OBSERVATORY IN THE EASTERN LIGURIAN SEA}

The Mediterranean basin is the second largest hotspot in the world for its rich terrestrial and coastal marine biodiversity [6], [7]. Moreover, in this relatively small bio-geographical area, fundamental physical, biological and chemical processes (such as surface wind forcing, buoyancy fluxes, lateral mass exchange, and deep convection) take place over shorter spatial and temporal scales if compared with oceans. This makes the Mediterranean a small-scale laboratory for understanding large scale processes characterizing global oceans and climate [8]. The Mediterranean Sea is a semiclosed water body divided into western and central-eastern basins, which are separated by the Strait of Sicily. The western basin consists of two deep basins: the LiguroAlgero-Provenc al Basin and the Tyrrhenian Sea. The central-eastern Mediterranean consists of three main deep basins: the Ionian, Aegean, and Levantine. The deepest point in the Mediterranean, $5121 \mathrm{~m} \mathrm{b.s.1.,} \mathrm{is} \mathrm{found} \mathrm{at} \mathrm{the}$ North side of the Matapan Trench, Ionian Sea, and the mean depth is about $1600 \mathrm{~m} \mathrm{[9].}$
The Ligurian Sea is a deep basin in the northernmost sector of the western Mediterranean, and is surrounded by the Alps and bordered on its west side by the Gulf of Lion and the Algero-Provençal Basin. On its eastern side it is limited by the northern Tyrrhenian Sea and by Corsica on the southern side [10].

From geological point of view, the Ligurian Sea basin comprises the northern portion of two distinct systems with different origin and evolution [10]. The western part is deep, reaching $>2600 \mathrm{~m}$ and oriented along a NE-SW axis and has a very thin continental crust. The eastern part, which is located on the eastern side of a seamount area and the seaward extension of Cape Corse (Corsica Island), is characterized by a very thick sedimentary cover [11]. From a topographic perspective, the Ligurian Sea is characterized by thermal contrasts between land and sea that give rise to specific local effects that influence the general circulation of both atmosphere and ocean, causing peculiar hydrodynamic and meteo-oceanographic features.

The Ligurian basin has a cyclonic permanent circulation pattern involving both the surface Modified Atlantic Water (MAW) and the lower Levantine Intermediate Water (LIW) [9]. This main cyclonic circulation (North-westward) is called Ligurian Provençal Current (LPC) and it is the result of two distinct northern streams: one (warmer) coming from the Tyrrhenian Sea through the Corsica Channel and the other (colder) flowing along the western Corsica coast [12]. The convergence of these currents generates a frontal system that separates the cold and salty central water from the coastal one [13], [14]. Although this structure is almost permanent, it shows an important seasonal and inter-annual variability, with more intense currents during winter period [13] and intense mesoscale activity related to the strong frontal system, as also detected by remote and in situ observations [15]. Furthermore, due to the interplay of these particular climatic, oceanographic and physiographic factors, the area is highly productive and hosts a rich and complex ecosystem. This high primary productivity is also sustained by vertical mixing and coastal upwelling, generated by the prevailing north-western wind, which pumps deep nutrients and other organic substances (river inputs) into the euphotic zone where they fertilize plankton communities. Moreover, deep-sea canyons are characterized by high organic matter availability which in turn sustains critical habitats for fish and decapods, including commercial species (i.e. the red shrimp Aristeus antennatus, the forkbeard Phycis blennoides). Several commercial species inhabiting the continental shelf, actually recruit on the adjacent slope or feed on species captured around 400-500 $\mathrm{m}$ (Merluccius merluccius). Last but not least, the entire Ligurian Sea is included in the "Pelagos Sanctuary" marine protected area, established to preserve the richness and variety of cetaceans living here with more than eight species [16], [17]. Nevertheless, it should not be forgotten that the Ligurian coasts are among the most urbanized and industrialized Italian areas and a very high human pressure (i.e. harbour activities, rail- and highways, coastal 
metropolitan areas, etc.) is actually coexisting with a very fragile and valuable environment that must be preserved and maintained. At the moment the Ligurian Sea hosts 26 SCI (Sites of Community Importance as defined by the European Commission Habitats Directive (92/43/EEC)), 6 national and regional MPAs (Marine Protected Areas) and 3 ILTER sites (International Long-Term Ecological Research Network). From this important knowledge of the Ligurian environment many datasets have been collected and the major challenge is now to integrate them in a comprehensive Information System: there is a huge heritage whose value can be increased only by sharing it in order to make possible an interdisciplinary approach to the understanding of the regional ecosystem functioning.

\section{PLANNING A NEW OBSERVING MODULE IN THE EASTERN LIGURIAN SEA}

A cabled deep seafloor multiparametric-observatory is under construction thanks to the official agreement between INGV (Istituto Nazionale di Geofisica e Vulcanologia) and DLTM (Liguria Cluster of Marine Technologies), a consortium of public and private institutions, SMEs and large industries (e.g., Finmeccanica) and Italian and International Research Centres (e.g., ENEA, CNR, CSSN and NATO-STO CMRE).

The aim is to ensure continuous acquisition of geophysical, oceanographic and biological data for a site of about $500-\mathrm{m}$ depth at $9-10 \mathrm{~km}$ offshore. The installation area was identified offshore Bonassola (North-East Ligurian Sea, Fig.1), a strategic site characterized by high-biodiversity, with several canyons, where coastal processes are directly affected by deep-sea dynamics due to the narrow continental shelf.

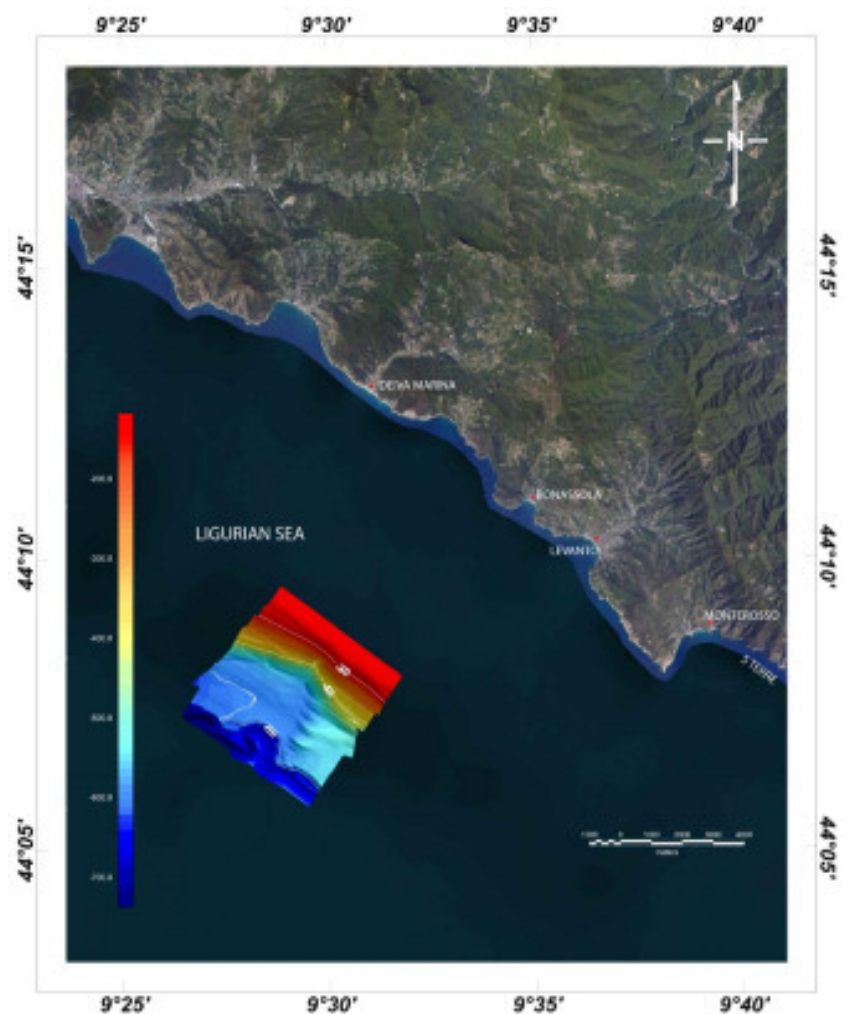

Fig. 1: Bathymetric map realized (by Istituto Idrografico della Marina Militare -Italian Navy) offshore Bonassola, in order to identify the best site for the deployment of the multiparametric observatory.

Moreover the presence of the MARECO station, a coastal laboratory of the CNR-IENI, will act as shore station. The Istituto Idrografico della Marina Militare, helped in identifying the best location, for the deployment of the multiparametric observatory. The bathymetric map (Fig.1) has been obtained using an EM302 Kongsberg multibeam system installed on ITS Aretusa (5304) hydrooceanographic ship. The bathymetric map shows the presence of a relatively flat area (light-blue area, between 500 - and $600-\mathrm{m}$ deep) suitable for the installation of the observatory.

The geographical location, scientific and operational requirements, and available resources influence the design and development of the observatory. In detail this observatory is composed by (Fig.2):

- a Submarine Instrumented Module (SIM)

- a Land Unit to receive and transmit data (Onshore FrontEnd, OFE)

- an umbilical cable for data transmission. 


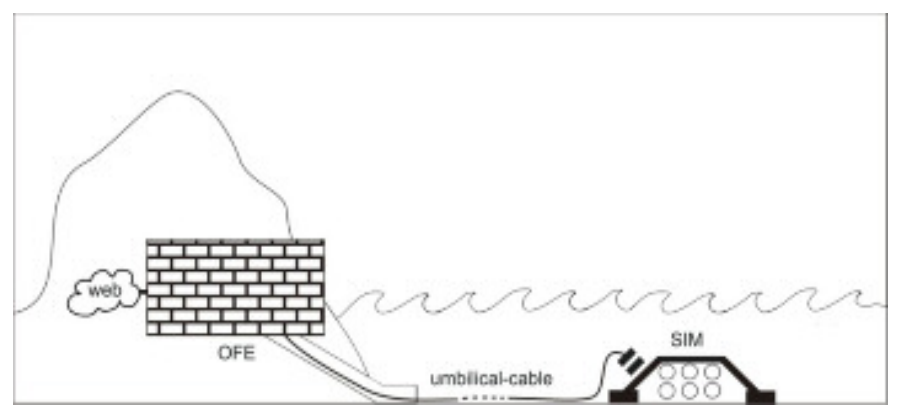

Fig. 2: The multiparametric observatory will be linked to MARECO coastal station trough a optic-fibre cable for data transmission.

The SIM will be realized in marine aluminium. The SIM will integrate sensors and housing for electronics and telemetry. In addition, titanium housings will be used in order to obtain a system suitable for long-term underwater permanence. The SIM will be instrumented by geophysical, oceanographic and biological sensors:

- 3-C broad-band seismometer

- High sensitivity vector magnetometer

- High sensitivity gravimeter

- ADCP-Acoustic Doppler Current Profiler

- CTD-Conductivity, Temperature, and Depth

- Pressure sensor

- Array of hydrophones

- Two underwater cameras and lights.

This new installation will allow technical tests of new devices and sensors, while providing and time-series data in real time. Each sensor will be powered and will provide data through the umbilical cable system to OFE in MARECO station. The umbilical cable will be deployed onshore in a borehole in the MARECO Station. This will ensure an additional protection avoiding damage by waves and surge. Others sensors will be suggested, designed and deployed by project partners during the whole lifespan of the observing module.

Data received by OFE will be transmitted via web to team of experts that will be responsible for the quality control of the data. The observatory will provide novel capabilities for data acquisition, distribution, modelling, planning and interactive control of oceanographic experiments.

\section{E-INFRASTRUCTURE AND KNOWLEDGE}

The e-infrastructure will be based on INSPIRE (Infrastructure for Spatial Information in Europe) services elements and will assure interoperability by adopting ISO standards, controlled vocabularies and WMS (Web Map Service), WFS (Web Feature Service), and WCS (Web Coverage Service) services.

The architecture will comprise six subsystems: four elements address the oceanographic science- and educationdriven operations of the integrated observatory, and two elements will provide core infrastructure services for the distributed, service-oriented integration and communication infrastructure, as well as the virtualization of computational and storage resources. Part of the collected data from the observing module will be stored in a DLTM local server, The acquired data will be also sent and integrated in the EMSO Data Management System, and available through the EMSO Portal. They will be also linked to other European Initiatives (e.g., EMODNet). Downstream services will be the result of joint activities of DLTM associates and PanEuropean initiatives (Fig.3).

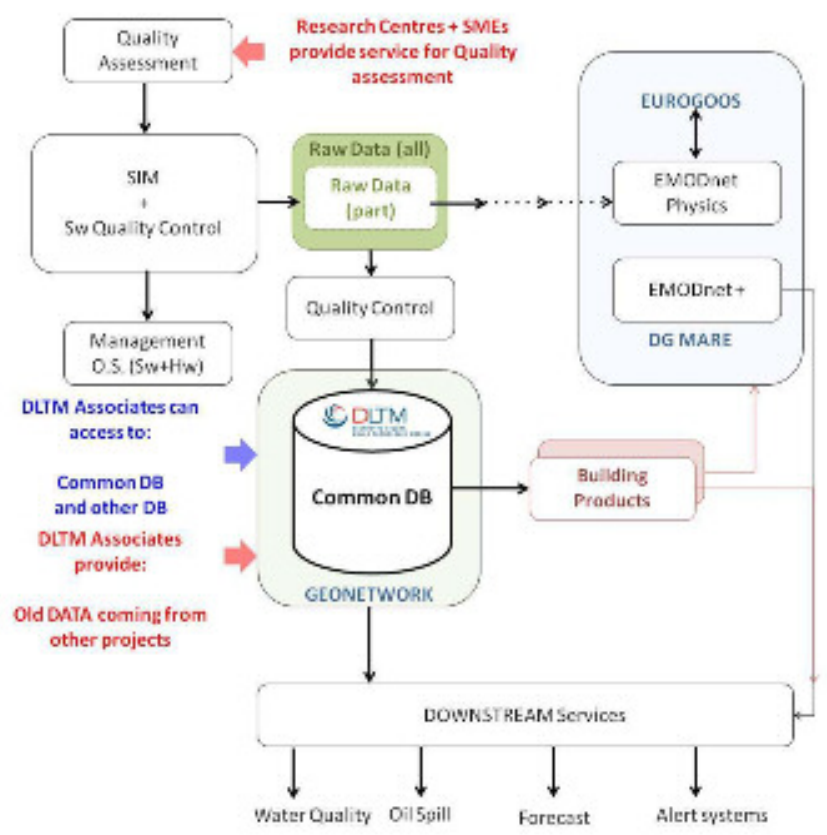

Fig. 3: Draft block diagram for data management and downstream services.

The observatory will perform geophysical and environmental long-term monitoring by acquiring seismological, geomagnetic, gravimetric, physical and oceanographic, hydro-acoustic and bio-acoustic measurements, and underwater images and videos.

A. Geophysical equipment (vector magnetometer, broadband seismometer and gravimeter) will furnish useful data for studying and monitoring submarine hazards as landslides, volcanic seamount activity, seismic activity and possible related tsunami events. The seismometer will extend the land-based network at sea, and monitor underwater active fault systems. Gravity data will provide new evidence concerning gravity variations related to phenomena like subsidence or mass variations. A magnetometer will collect data about the earth's magnetic field, its variations and possible anomalies related to geological sources.

$B$. Under a biological point of view, the observatory will follow the objectives of the Marine Strategy Framework Directive (MSFD) in relation to different descriptors such as D1 (Biodiversity), D3 (commercial species) and D4 (food webs) by: 
- Providing an exhaustive local faunistic checklist, as preliminary tool for deep-sea ecosystem exploration and conservation.

- Upgrading the knowledge on the ethology of deep-sea species, including those of commercial relevance.

- Recompiling time series of visual observations to infer species activity rhythms and resulting community dynamism on a diel and seasonal base.

- Using habitat data to foster a multidisciplinary analysis integrating species counts and assemblage structure in the context of the surrounding environmental changes.

- Promoting Citizen Science approaches with stored videomaterial.

C. New technologies will be included in the observatory. A sea floor-oriented camera will allow monitoring horizontal movements of deep-sea species (including those of commercial value) and provide important and useful information also for fisheries management [18]. The most innovative aspect with important biological implications lies in the deployment of a second, vertical-oriented, acoustic video camera. This will help to monitor vertical migrations of macrozooplankton (mainly euphausiids, the so-called krill) and micronekton (especially myctophid fishes) which play an important role in mesopelagic communities acting as top-down controllers. Moreover, zooplankton migration patterns and seasonal variability will be investigated too through the appropriately analysis of backscatter data, by ADCP sensor [16]. The acoustic video camera could be also improved with a blue-light led to attract large squids, the main food for sperm whale, one of the cetacean species living in the area. An array of hydrophones will be used for passive acoustic detection of cetaceans. Monitoring of marine mammals can help us understand their population trends in relation to climate changes and human impact. The study of the marine mammals is relevant also considering the recent proposal of Italian government to forbid the use of air guns in geophysical exploration. Visual observations captured by the camera will be analysed by software tools for automatic detection and image classification [19], [20]. Images will be studied and developed for habitat and ecosystem monitoring and mapping. In particular, long-term time-lapse acquisition will be considered for providing information on seasonal fluctuations of the environmental parameters.

$D$. Persistent monitoring of the dynamic processes will be done by using a long-range ADCP will allow to obtain longterm time series of current speed vertical profiles throughout the water column, and to monitor the link of near-surface waters with the deep ones. The site will be a permanent observation point of the bottom thermohaline circulation and a stable monitoring point for habitats, to assess cause-and-effect relationships between environmental changes and ecological variations (e.g., global change). These long time series will then be used to identify the dominant temporal and spatial scales of interest that will then be sampled through the use of robotic networks and surveys of opportunity.

\section{CONCLUSIONS}

In the last decade monitoring of marine deep environment has been an important target for the European Community. This important message was already received and implemented by the several Research Centres that operate in the Liguria Region. This can be easily confirmed by the large amount of projects and papers concerning this kind of studies in the area [10]. A new observing module in the eastern side of the Ligurian Sea represents a unique effort for merging common objectives, human resources, skills and expertise, with a private and public partnership, that will join their knowledge capabilities and will increase networking and cooperation among business, government and research facilities. The observing module will try for two main objectives: to be a platform test for new instruments and to collect new long-term time series data. In detail, in strict cooperation with the EMSO Ligurian Sea node French side, the prototype will investigate sub-sea geophysics, slope stability, biogeochemical fluxes and marine ecology, acquiring geophysical, biological and oceanographic data. Moreover the presence of cameras and hydrophones will allow to monitor the presence of cetaceans. In coastal regions, bottlenose dolphins long-term patterns of occurrence are fundamental to better understand relationships between dolphins and their habitat, including human activities such as fishing and vessel traffic [21]. The presence of this new observation point will surely enlarge the knowledge on the relationship amongst coastal (about $600 \mathrm{~m}$ of depth) and offshore (about $2000 \mathrm{~m}$ of depth in DYFAMED site) processes in the Ligurian Sea. Moreover, the real-time data will support the evaluation and calibration of the models to improve the forecast and hindcast data products (long and short term). These tools will be fundamental to improve the citizen services as governance, prevention and emergency management (e.g., in case of dispersion of pollutants).

\section{REFERENCES}

[1] M.M.R., Best, P., Favali, L., Beranzoli, M., Cannat, N.M., Çağatay, J.J., Dañobeitia, E., Delory, H., de Stigter, B., Ferré, M., Gillooly, F., Grant, P.O.J., Hall, V., Lykousis, J., Mienert, J.M.A., de Miranda, G., Oaie, V., Radulescu, J.-F., Rolin, H.A., Ruhl, C., Waldmann. EMSO: A distributed infrastructure for addressing geo-hazards and global ocean change. Oceanography 27(2), 167-169, doi:http://dx.doi.org/10.5670/ oceanog.2014.52, 2014.

[2] P., Favali, R., Person, C.R., Barnes, Y., Kaneda, J.R., Delaney, S.-K., Hsu. Seafloor Observatory Science. In: J. Hall, D.E. Harrison, D. Stammer (eds.), Proceedings of the OceanObs'09: Sustained Ocean. Observations and Information for Society conference 2, Venice, Italy, 21-25 September 2009, ESA Publication WPP-306 ISSN:1609-042X, doi:10.5270/OceanObs09.cwp28, 2010.

[3] ESFRI (European Strategy Forum on Research Infrastructures), Strategy Report on Research Infrastructures, Roadmap 2010, 2011. ISBN:978-92-79-16828-4, doi:10.2777/23127, http://cordis.europa. eu/ esfri/ road map.htmS.

[4] H.A., Ruhl, M., André, L., Beranzoli, M.N., Çağatay, A., Colaço, M., Cannat, J.J., Dañobeitia, P., Favali, L., Géli, M., Gillooly, J., Greinert, P.O.J., Hall, R., Huber, J., Karstensen, R.S., Lampitt, K.E., Larkin, V., Lykousis, J., Mienert, J.M.A., de Miranda, R., Person, I.G., 
Priede, I., Puillat, L., Thomsen, C., Waldmann. Societal need for improved understanding of climate change, anthropogenic impacts, and geo-hazard warning drive development of ocean observatories in European Seas, Progress in Oceanography, 91, 1-33, doi:10.1016/j.pocean.2011.05.001, 2011.

[5] P., Favali, F., Chierici, G., Marinaro, G., Giovanetti, A., Azzarone, L., Beranzoli, A., De Santis, D., Embriaco, S., Monna, N., Lo Bue, T., Sgroi, G., Cianchini, L., Badiali, E., Qamili, M., De Caro, G., Falcone, C., Montuori, F., Frugoni, G., Riccobene, M., Sedita, G., Barbagallo, G., Cacopardo, C., Calì, R., Cocimano, R., Coniglione, M., Costa, A., D'Amico, F., Del Tevere, C., Distefano, F., Ferrera, V., Giordano, M., Imbesi, D., Lattuada, E., Migneco, M., Musumeci, A., Orlando, R., Papaleo, P., Piattelli, G., Raia, A., Rovelli, P., Sapienza, F., Speziale, A., Trovato, S., Viola, F., Ameli, M., Bonori, A., Capone, R., Masullo, F., Simeone, L., Pignagnoli, N., Zitellini, F., Bruni, F., Gasparoni, G., Pavan. NEMO-SN1 Abyssal Cabled Observatory in the Western Ionian Sea, IEEE J. Oceanic Engineering, 38, 2, 358-374, doi:10.1109/joe.2012.222.4536, 2013.

[6] R., Danovaro, J.B., Company, C. Corinaldesi, G., D’Onghia, B., Galil, C., Gambi, A.J., Gooday, N., Lampadariou, G.M., Luna, C., Morigi, K., Olu, P., Polymenakou, E., Ramirez-Llodra, A., Sabbatini, F., Sardà, M., Sibuet, A., Tselepides. Deep-Sea Biodiversity in the Mediterranean Sea: The Known, the Unknown, and the Unknowable. PLoS ONE, 5, 8, e11832, 2010.

[7] F., Médail, P., Quézel. Biodiversity hotspots in the Mediterranean basin: Setting global conservation priorities. Conservation Biology, $13,1510-1513,1999$

[8] G.E., Borzelli, M., Gacic, P., Lionello, P., Malanotte-Rizzoli. The Mediterranean Sea: Temporal Variability and Spatial Patterns. John Wiley \& Sons, 2014.

[9] C., Millot. Circulation in the Western Mediterranean Sea. J. Marine Systems, 20, 1-4, 423-442, 1999.

[10] R., Cattaneo Vietti, G., Albertelli, S., Aliani, S., Bava, G., Bavestrello, L., Benedetti Cecchi, C.N., Bianchi, E., Bozzo, M., Capello, M., Castellano, C., Cerrano, L., Cutroneo, G., Diviacco, M., Fabiano, M., Faimali, M., Ferrari, G.P., Gasparini, M., Locritani, L., Mangialajo, V., Marin, M., Moreno, C., Morri, L., Orsi Relini, L., Pane, C., Paoli, M., Petrillo, P., Povero, R., Pronzato, G., Relini, G., Santangelo, S., Tucci, L., Tunesi, M., Vacchi, P., Vassallo, L., Vezzulli, M., Wurtz. The Ligurian Sea: present status, problems and perspectives. Chem Ecol 26, 319-340, 2010.

[11] F., Fanucci, R., Nicolich. Il Mar Ligure. Nuove acquisizioni sulla natura, genesi ed evoluzione di un 'bacino marginale', Mem. Soc. Geol. It. 27, 97-110, 1984
[12] M., Astraldi, G.P., Gasparini. The seasonal characteristics of the circulation in the North Mediterranean Basin and their relationship with the atmospheric-climatic conditions, J. Geophys. Res. 97(C6), 9531-9540, 1992.

[13] M., Astraldi, G.P., Gasparini, S., Sparnocchia. The Seasonal and Inter-Annual Variability in the Ligurian Provençal Basin. Coast. and Estuar. Stud.46, 93-113, 1994

[14] G.P., Gasparini, G., Zodiatis, M., Astraldi, C., Galli, S., Sparnocchia. Winter Intermediate Water Lenses in the Ligurian Sea. J. Marine Systems.20, 319-332, 1999.

[15] S., Vignudelli, P., Cipollini, M., Astraldi, G.P., Gasparini, G., Manzella. Integrated use of altimeter and in situ data for understanding the water exchanges between the Tyrrhenian and Ligurian Seas. Journal of Geophysical Research: Oceans (19782012), 105, C8, 19649-19663, 2000

[16] R., Bozzano, E., Fanelli, S., Pensieri., P., Picco., M.E., Schiano. Temporal variations of zooplankton biomass in the Ligurian Sea inferred from long time series of ADCP data. Ocean Sci., 10, 93-105, 2014.

[17] G., Notarbartolo-Di-Sciara, T., Agardy, D., Hyrenbach, T., Scovazzi, P., Van Kalveren. The Pelagos Sanctuary for Mediterranean marine mammals. Aquatic Conservation: Marine and Freshwater Ecosystems 18: 367-391, 2008.

[18] J., Aguzzi, J.B., Company, C., Costa, M., Matabos, E., Azzurro, A, Mànuel, P., Menesatti, F., Sardà, M., Canals, E., Delory, D., Cline, P., Favali, S.K., Juniper, Y., Fujiwara, J.J., Chiesa, L., Marotta, I.M., Priede. Challenges to the assessment of benthic populations and biodiversity as a result of rhythmic behaviour: Video solutions from cabled observatories. In: R.N., Gibson, R.J.A., Atkinson, J.D.M., Gordon, R.N., Hughes, D.J., Hughes, I.P., Smith (eds.), Oceanography and Marine Biology: An Annual Review, 50, 235-286, Taylor \& Francis, ISSN:0078-3218, 2012.

[19] S., Marini, A., Griffa, A., Molcard. Prototype imaging devices for jelly zooplankton a low-consumption, stand-alone system for image detection,analysis. Sea Technology 54, 44-48, 2013.

[20] L., Corgnati, L. Mazzei, S., Marini, S., Aliani, A., Conversi, A., Griffa, B., Isoppo, E., Ottaviani. Automated Gelatinous Zooplankton Acquisition and Recognition, Computer Vision for Analysis of Underwater Imagery (CVAUI), 2014 ICPR Workshop on ,IEEE,1,8. Doi: 10.1109/CVAUI.2014.12, 2014.

[21] G., Gnone, S., Nuti, M., Bellingeri, R., Pannoncini, D., Bedocchi. Spatial behaviour of Tursiops truncatus along the Ligurian Sea cost: preliminary results. Biologia Marina Mediterranea, 13(2), 272-273, 2006. 